\title{
Ethanol Sclerosis: One of the Best Treatments for Thymic Cyst in Very Elderly Patients?
}

\author{
Yoshifumi Hirano, Toshio Shimada, Yoshihisa Kinoshita, Yo Murakami, Kanako Kobayashi, \\ Hiroyuki Yoshitomi, Jun Kitamura, Kazuya Sano, Kazuaki Tanabe, Yutaka Ishibashi and Rinji Murakami
}

An 83-year-old female patient with a giant thymic cyst that was successfully treated by percutaneous aspiration and ethanol injection. The patient had complained of coughing and chest discomfort for several years. A chest $X$-ray film revealed the shadow of a large abnormal mass in the anterior mediastinum. We diagnosed it as a thymic cyst. The patient refused surgery because of her age. We chose a less invasive therapy, namely, ethanol sclerosis of the cyst. The cyst was successfully treated without any complications, and no recurrence was found at the one-year follow-up. This therapy may be one of the best treatments for thymic cysts, especially in very elderly patients.

(Internal Medicine 36: 716-719, 1997)

Key words: mediastinal cyst, less invasive treatment, computed tomography (CT), congenital

\section{Introduction}

Thymic cyst is a relatively uncommon disease. From 5 to $10 \%$ of all anterior mediastinal tumors are thymic cysts, and its etiology has been considered congenital in most of cases (1). When these cysts show enlargement, or when symptoms develop due to compression or infection from adjacent organs, treatment has to be considered in these clinical settings. Although there are several reports of ethanol sclerosis on renal cysts $(2,3)$, hepatic cysts $(4,5)$ and cysts in other organs, there are few reports describing the treatments available for thymic cysts. In this case, we treated a growing thymic cyst in a very elderly patient with aspiration and ethanol injection. This less invasive treatment was chosen because of patient's age and her refusal to undergo surgery.

\section{Case Report}

An 83-year-old female patient had complained of cough and chest discomfort over several years. She visited a local physician for these symptoms, and a shadow indicating an abnormal mass was discovered in the anterior mediastinum. She was referred to Shimane Medical University Hospital for further examination and treatment. A chest X-ray showed a spheroidal mass in the anterior mediastınum. The mass had a smooth contour and homogeneous radiodensity. Computed tomogra- phy $(\mathrm{CT})$, echocardiography and magnetic resonance imaging were used to examine the characteristics of the mass in detail. CT scans (GE CT/T 9800 Highlight, General Electric Inc. Milwaukee, USA), taken at $10 \mathrm{~mm}$ intervals from the thoracic inlet to the diaphragm, showed encapsulated fluid retention at the anterior mediastinum. Echocardiography (Toshiba SSH160A, Toshiba Medical Inc. Tokyo) was performed from the 3rd intercostal space, using a $3.5 \mathrm{MHz}$ transducer. The echocardiogram showed that the mass was a thin-walled cyst. The magnetic resonance imaging (Signa 1.5 Tesla, General Electric Inc.) revealed low signal intensity on T1-weighted images and high signal intensity on T2-weighted images. We therefore tentatively diagnosed the mass as a thymic cyst. Because the cyst had been growing in size (Fig. 1), and the patient's cough and chest discomfort had been worsening for several years, we recommended complete surgical removal of the cyst. The patient, however, rejected our recommendation because of her age. Finally, we decided on ethanol sclerosis as a less invasive treatment for the cyst. The cyst was punctured parasternally from the right 3rd intercostal space, using an introducer (6 French, Terumo Inc. Tokyo) under echocardiographic guidance. A pigtail catheter (6 French, Terumo Inc.) with a guidewire $(0.89 \mathrm{~mm}$ angle-type, Terumo Inc.) was inserted through the introducer into the cyst with fluoroscopic assistance. First, a small amount of fluid was aspirated for laboratory examination. Next, $10 \mathrm{ml}$ of $1 \%$ lidocaine hydro-

From the Fourth Department of Internal Medicıne, Shımane Medıcal Unıversity, Shımane

Received for publication November 5, 1996. Accepted for publicatıon June 10, 1997

Reprint requests should be addressed to Dr Yoshıfumı Hırano, the Fourth Department of Internal Medıcıne, Shımane Medıcal Unıversity, 89-1 Enya-cho, Izumo, Shimane 693 

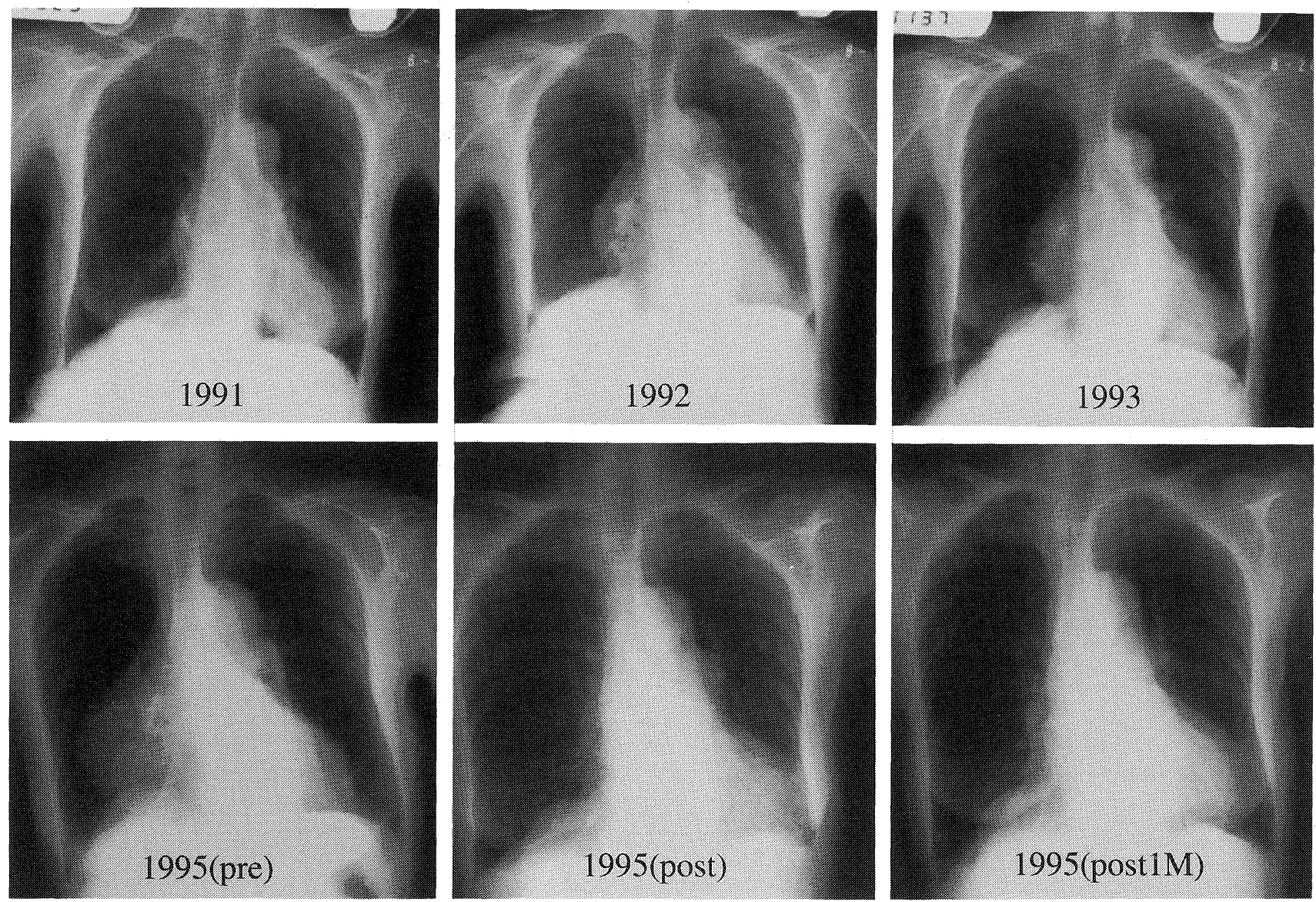

Figure 1. A series of 6 chest X-ray films show the progressive enlargement of the mass from 1991 to 1995 . The chest X-ray film of September 12 in 1995 (pre) shows the mass just before ethanol sclerosis, while that of October 26 in 1995 (post) shows marked diminution of the mass immediately after ethanol sclerosis. The chest X-ray film of November 24 in 1995 (post 1 month) shows marked diminution of the mass and the absence of recurrence one month after the ethanol sclerosis.

chloride was injected through the catheter into the cyst as a local anesthetic, and then $20 \mathrm{ml}$ of contrast medium (Iohexol $754.9 \mathrm{mg} / \mathrm{ml}$ ) was injected to check for possible leakage to adjacent organs. We confirmed that there was no leakage to the adjacent organs.

The entire amount of fluid in the cyst was aspirated (a total $254 \mathrm{ml}$ ), and after injection of a supplementary dose of $10 \mathrm{ml}$ of $1 \%$ lidocaine hydrochloride, $25 \mathrm{ml}$ of $10 \%$ ethanol was injected into the cyst, and $20 \mathrm{ml}$ of $50 \%$ ethanol was subsequently injected for sclerosis. The patient complained of chest pain, and $10 \mathrm{ml}$ of $1 \%$ lidocaine hydrochloride and $0.1 \mathrm{mg}$ of buprenorphine hydrochloride were injected intravenously for pain relief. One minute after additional $80 \mathrm{ml}$ of 50\% ethanol was injected, almost all of the ethanol was aspirated. Finally, the pigtail catheter was placed for drainage. The following day, the pigtail catheter was removed after confirming that no fluid was drained.

The $\mathrm{pH}$ of the aspirated fluid was 6.5 , with an osmolarity of $292 \mathrm{mOsm} / \mathrm{l}$; it contained $1.8 \mathrm{~g} / \mathrm{dl}$ protein, $0.7 \mathrm{~g} / \mathrm{dl}$ albumin, 13 $\mathrm{mg} / \mathrm{dl}$ cholesterol, $10 \mathrm{mg} / \mathrm{dl}$ glucose, and less than $0.2 \mathrm{mg} / \mathrm{dl} \mathrm{C}-$ reactive protein (CRP). The Rivalta reaction was positive. The fluid contained neither inflammatory nor malignant cells. The patient's plasma ethanol concentration was $20 \mathrm{mg} / \mathrm{dl}$ at 30 minutes and $10 \mathrm{mg} / \mathrm{dl}$ after 90 minutes after the ethanol injection. The entire procedure was completed within normal limits (below $30 \mathrm{mg} / \mathrm{dl}$ ).

After this treatment, the patient's prognosis has been uneventful, and she has felt much better than before. She was discharged one month later after confirmation by chest X-ray and CT scans (Figs. 1,2) that there was no recurrence. At the one-year follow-up, no recurrence was found.

\section{Discussion}

According to the literature, thymic cysts comprise from 1.5 to $2.1 \%$ of all mediastinal tumors and from 5 to $10 \%$ of all the thymic tumors (6). Krech classified thymic cysts into congenital, inflammatory and tumorous cysts (7). Most thymic cysts are congenital.

From the pathological standpoint, thymic cysts commonly have a thin-walled lining of mesothelial cells and contain a transparent yellowish fluid. In the clinical setting, it is important to differentiate thymic cysts from malignant tumors. Judging 

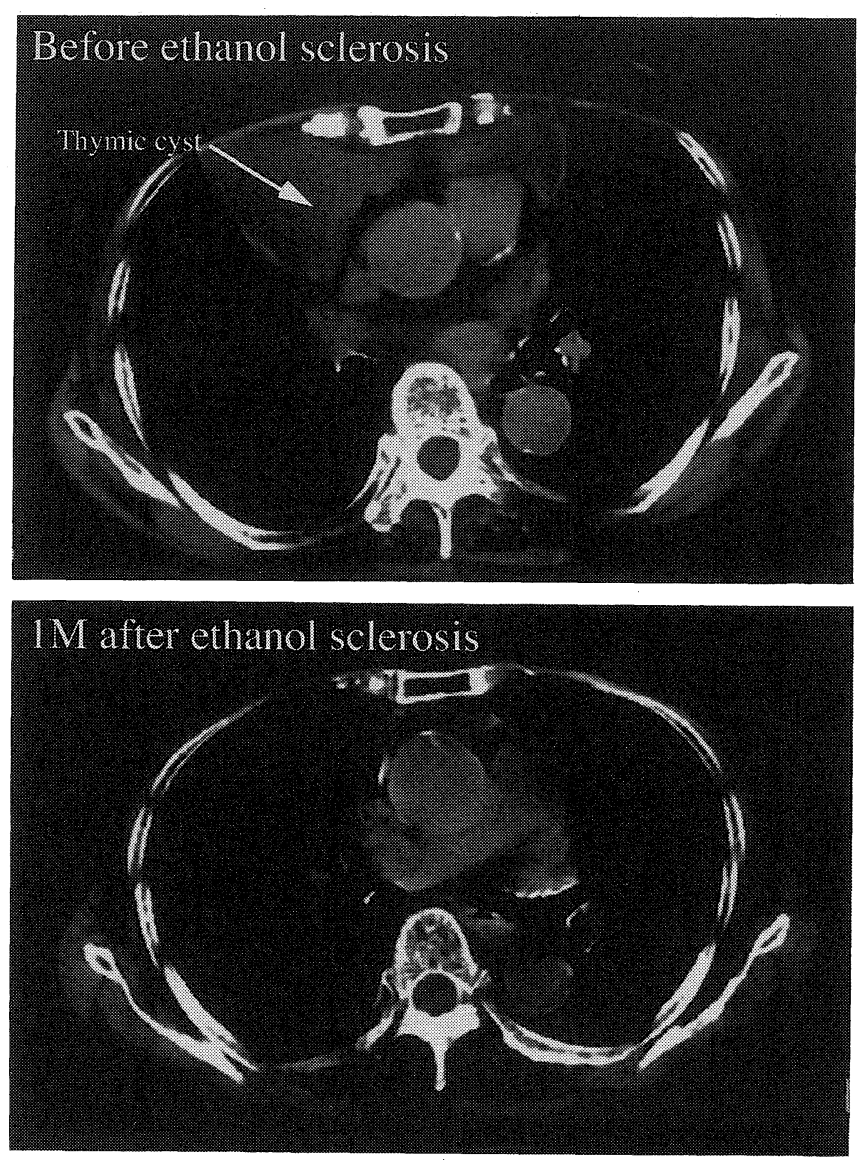
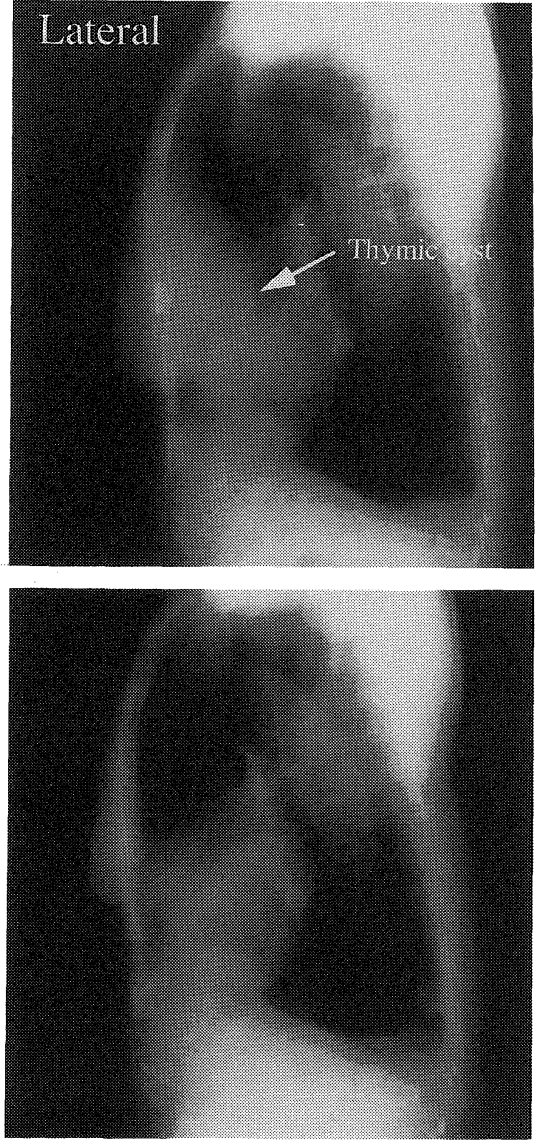

Figure 2. The left panels show computed tomograms. The upper left panel shows a giant mass with homogeneous radiodensity between the heart and the anterior thorax before ethanol sclerosis. The lower left panel shows marked diminution of the mass one month after ethanol sclerosis. The right panels show lateral chest X-ray films. The arrow in the upper right panel shows a giant mediastinal mass before ethanol sclerosis. The lower right panel shows marked diminution of the mass and no recurrence one month after ethanol sclerosis.

from its fluid contents and from the appearance of CT scans, echocardiograms (8) and magnetic resonance images, we considered that the thymic cyst in the present case was probably congenital. Because the cyst had increased in size over a period of several years, and the patient had felt worsening chest discomfort and cough, we first recommended complete surgical removal of the cyst. The patient rejected our recommendation because of her age, and we therefore decided upon ethanol sclerosis as an alternative treatment. Ethanol sclerosis has been commonly used for treatment of hepatic and renal cysts (2-5), but not, however, for mediastinal cysts. In fact, only two papers have been published on the use of ethanol sclerosis for mediastinal cysts, including our own previous report on pericardial cyst $(9,10)$. However, the other previous report (9) did not describe the entire procedure in detail. We have endeavored to describe the total procedure in detail, to make it possible to perform ethanol sclerosis safely. The mediastinum contains many vital organs and it is important to consider possible complications before proceeding with ethanol sclerosis. Cystography can be helpful in confirming any possible leakage into surrounding tissues, and in preventing other possible complications resulting from ethanol sclerosis. We found no leakage in the present case. Ethanol injection into mediastinal cysts usually causes severe chest pain, and introducing a local anesthesia into the cyst helps to relieve the chest pain during ethanol injection. Ethanol sclerosis has not yet been established for mediastinal cysts. Because alcoholic intoxication has been reported after ethanol sclerosis for hepatic tumors, we carefully monitored the plasma ethanol concentration after ethanol injection in order to confirm the safety of the procedure. The plasma ethanol concentration was kept within the normal range in the present patient. The results of this case suggest that ethanol sclerosis can be a safe and useful treatment for mediastinal cysts, especially in elderly patients. In elderly or incapacitated patients, open chest surgery for resection of a mediastinal cyst may be too invasive; therefore, ethanol sclerosis may be one of the best alternative treatments in this clinical situation. 


\section{Ethanol Sclerosis for Thymic Cysts}

\section{References}

1) Morrison IM. Tumours and cysts of the mediastinum. Thorax 13: 294, 1958.

2) Bean WJ. Renal cysts: Treatment with alcohol. Radiology 138: 329, 1981.

3) Ellman BA, Parkhill BJ, Curry TS, Marcus PB, Peters PC. Ablation of renal tumors with absolute ethanol: A new technique. Radiology 141: $619,1981$.

4) Bean WJ, Rodan BA. Hepatic cysts: Treatment with alcohol. Am J Roentgenol 144: 237, 1985.

5) Shiina $S$, Tagawa $K$, Unuma $T$, et al. Percutaneous ethanol injection therapy of hepatocellular carcinoma: Analysis of 77 patients. Am J Roentgenol 155: 1221, 1990.

6) Nelson TG, Shefts LM, Bowers WF. Mediastinal tumors: An analysis of 141 cases. Dis Chest 32: 123, 1957.

7) Krech WG. Thymic cyst: A review of the literature and report of two cases. J Thorac Surg 27: 477, 1954.

8) Hynes JK, Tajik AJ, Osborn MJ, Orszulak TA, Seward JB. Twodimensional echocardiographic diagnosis of pericardial cyst. Mayo Clin Proc 58: 60, 1983.

9) Malde HM, Kedar RP. Chadda DJ. Ethanol sclerosis of a mediastinal cyst. Can Assoc Radiol J 44: 310, 1993.

10) Kinoshita $Y$, Shimada $T$, Murakami $Y$, et al. Ethanol sclerosis can be a safe and useful treatment for pericardial cyst. Clin Cardiol 19: 833, 1996. 